\title{
Oğuz Grubu Türk Lehçelerinde Fiil Tamlayıcı İlişkisi Bağlamında Yönelme (+(y)A) ve Belirtme (+(y)I/U) Durum Biçimbirimlerinin Farklı Kullanımı: Act-, Bak-Döv-, Gül- ve Seyret- Fiilleri Örneği
}

\author{
Arş. Gör. Hüseyin Gökçe \\ İnönü Üniversitesi, Fen Edebiyat Fakültesi \\ Türk Dili ve Edebiyatı Bölümü \\ h.gokce16@hotmail.com
}

Öz

Türk lehçeleri ve Anadolu ağızlarında durum biçimbirimlerinin birbirlerinin yerine kullanıldığ birbirinin yerine kullanılır. Söz konusu kullanım aynı grup içerisinde yer alan Oğuz grubu Türk lehçelerinde de görülür. Bu lehçelerde ortak olarak -aynı ya da yakın anlamdakullanılan acl-, bak- döv-, gül-ve seyret- fiilleri bazen yönelme bazen belirtme biçimbirimli tamlayıcılar ile kullanılmıştır. Bu çalışmada mezkûr fiillerin farklı biçimbirimlerle kullanılmasının sebepleri açıklanmaya çalışılmıştır. Bahsi geçen fiiller, daha doğru sonuçlara ulaşabilmek amacıyla her bir oğuz lehçesi içerisinde ayrı ayrı değerlendirilmiştir. Bir dil ya da lehçe içerisindeki durum biçimbirim değişikliği zaman içerisinde meydana gelir. Dolayısıyla fiilde görülen bu değişikliklerin sebeplerinin açıklanabilmesi için o fiilin eski dönemlerde hangi anlamda hangi biçimbirimlerle kullanıldığı bilinmelidir. Bu çalışmada da acl-, bak- döv-, gül- ve seyret- fiillerinin eski dönemlerde hangi anlamda hangi biçimbirimle kullanıldığına değinilmiştir.

Anahtar Kelimeler: İstem, biçimbirim, yönelme, belirtme, Oğuz lehçeleri.

\section{Different Use of Accusative $(+(y) I / U)$ and Dative $(+(y) A)$ Morphemes in the Context of Verb Completion Relationship in Oguz Group Turkish Dialects: Example of the Verbs Act-, Bak-Döv-, Gül- and Seyret-}

\begin{abstract}
In Turkish dialects and Anatolian dialects, there are many examples where situational morpheme is exchanged. In particular, the case of $+(y) A$ and $+(y)$ I morphemia is often used interchangeably. The said use is also seen in the Turkish dialects of the Oğuz group, which are included in the same group. The verbs ac1-, bak- döv-, gül- and seyret- are used in these dialects in the same sense, sometimes used with dative and sometimes accusative morpheme complement. In this study, reasons of using the said verbs with different morpheme are tried to be explained. These verbs were evaluated separately in each dialect in order to achieve more accurate results. Morpheme change in a language or dialect occurs over time. Therefore, in order to explain the reasons of these changes in the verb, it should
\end{abstract}


be determined in what sense and with which morpheme the verb was used in the old times. In this study, it was also explained in what sense and with which morpheme the verbs acl-, bak-, döv-, gül- and seyret- were used in the old periods.

Keywords: Valency, morpheme, dative, accusative, Oguz dialects. 


\section{GİRIŞ}

Türkçede durum eklerinin fiille kurduğu ilişki konusunda birçok çalışma yapılmıştır. Araştırmacılar tarihî ve çağdaş Türk dillerinden örnekler vererek bu konu üzerine eğilmiş ve farklı bakış açıları getirmiştir. Son dönemlerde bu konu, istem (valenz) üzerine yapılan çalışmalarda ele alınmıştır.

Fiillerin istem konusu ile ilgili ilk ayrıntılı çalışma, Tahir Kahraman tarafından yapılmıştır (1996). Kahraman, Türkçe Sözlük'ten ve edebî eserlerden tarayarak tespit ettiği fiillerden hareketle bu fiillerin hangi durum ekli tamlayıcıları hangi şartlarda alabildiğini belirtmiş̧tir. Kahraman'ın ardından Sev de (2011) sözlükler ve edebî eserlerden hareketle etfiiliyle kurulan birleşik fiillerin aldığı tamlayıcıların listesini verir. Benzer bir çalışma da Ölker tarafından yapılmıştır (2018, s. 56-59). Yapılan bu çalışmalar dışında istem konusu ile ilgili birçok tez çalışması da hazırlanmıştır. ${ }^{1}$ Doğan tarafından hazırlanan "Türkiye Türkçesi Fiillerinde İsteme Göre Anlam Değişiklikleri" (2011) isimli doktora tezi, istem konusunu ele alan en kapsamlı tez çalışmalarından biridir. Ayrıca Köktürkçe ve Karahanlı Türkçesi, Eski Anadolu Türkçesi, Türkiye Türkçesi, Yeni Uygur Türkçesi, Özbek Türkçesi, Azerbaycan Türkçesi ve Türkmen Türkçesi'nde istem konusu üzerine, makale düzeyinde çalışmalar da yapılmıştır (Dinar, 2010; Özkan, 1999, 2011; Bilveren 2015; Erdem, 2004, 2006).

Bahsi geçen bu çalışmalar genel olarak fiillerin tarihî ve çağdaş Türkçedeki durum biçimbirimleri ile ilişkisini ele alır. $\mathrm{Bu}$ çalışmalarda özellikle $+(y) A$ ve $+(y) I / U$ biçimbirimlerinin sıklıkla birbirinin yerine kullanıldığı görülmüştür. $\mathrm{Bu}$ sebeple bazı araştırmacılar Anadolu ağızlarındaki, çağdaş lehçelerdeki veyahut tarihî lehçelerdeki $+(y) A$ / $+(y) I / U$ değişimi üzerine çalışmalar yapmış ve bu değişimin sebeplerini açıklamaya çalışmışlardır. Türkçede $+(y) A /+(y) I / U$ değişmesine sebep olarak bugüne kadar ileriye sürülen görüşler şu şekildedir.

Korkmaz, Eski Türkçenin (ET) n lehçesinde görülen +ag / +eg belirtme durum biçimbiriminin Batı Anadolu ağızlarında $+(y) A$ olarak devam ettiğini ifade eder ve Batı Anadolu ağızlarında sıklıkla görülen $+(y) A /+(y) I / U$ değişimini buna bağlar. Ancak Korkmaz, bu değişimlerin bazılarının ünlü daralmasıyla ilgili olduğunu da belirtir (Korkmaz, 1980, s. 29-40). Buran, bu konuda büyük ölçüde Korkmaz'la aynı fikirde olduğunu ifade etse de bu değişimin kısmen fiillerin rejimi ile ilgili olduğunu belirtir. Bazı fiillerin ismi her iki hâlle de kabul etmesinin, bu değişimin bir başka sebebi olduğunu belirten Buran, bu durumu beni çağır- / bana çağır-, seni beğen- / sana beğen- gibi örneklerle açiklar (Buran, 1996, s. 125). Günay bu durumun aslında geçişli olan bazı fiillerin geçişsiz fiil işlemi görmesiyle ortaya çıkmış gelip geçici bir durum olduğunu belirtir (2003, s. 110)

Gülsevin, Uşak ve Yöresi Ağızları'nda tespit edilen bazı örneklerde $+(y) I / U$ durum biçimbirimin yönelme işlevinde kullanıldığına değinir ve bu durumu ünlü daralması ile açıklar. Ancak bazı fiillerin tamlayıcılarında görülen $+(y) I / U$ biçimbirimin yönelme işlevinde kullanılmasının fiil tamlayıcı ilişkisiyle ilgili olabileceğini de belirtir (2002, s. 86).

İlker, Manisa ağızlarında görülen $+(y) A /+(y) I / U$ değişmelerinin fiil tamlayıcı ilişkisine bağlanamayacağını belirterek bu değişimi dört farklı sebeple açıklar. Birincisi, aynı kavram

\footnotetext{
${ }^{1}$ İstem konusunda Doktora tezi olarak, Nasrullah Özsoy (1993), Aysun Demirez Güneri (2007), Iş1l Aydın Özkan (2018), Yüksek Lisans tezi olarak, Arzu Özdemir (2004), Derya Acar (2005), Yasemin Kaya (2007), Dursun Ahmet Atacık (2008), Hilal Uzunboy (2008), Vildan Emre (2008), Nesrin Arı (2010) Seçkin Uysal (2010), Alper Kara (2011), Tuba Arı Özdemir (2012), Hanife Çiçekli (2013), Ferhat Baytürk (2015) çalışmıştır.
}

SEFAD, 2021; (45): 143-158 
alanına sahip fiiller, zihinsel tasavvurda birbirine çok yakın şekilde kodlanır. Bu nedenle bu tür fiillerin tamlayıcıları birbirinin yerine kullanılabilir. İkincisi, fiille ilişkili olan bütün istemler / tamlayıcilar doludur, ancak yüzey yapıya geçerken bunlarda bir boşalma meydana gelir. Bu boşalma bazen zihinde yerleşmiş biçimbirimlerin taşınması ya da birleşmesinden bazen de fonetik eğilimlerden dolayıdır. Söz konusu taşınma, yönelme yerine yüklemenin görüldüğü örneklerde daha etkilidir. Derin yapıda "ben size yaşımı mı söyleyeyim" şeklinde kodlanan cümle Manisa ağzında yüzey yapıya "Yaşıma mı söyleyeyim?" şeklinde çıkar. Bu cümlede, tümleçteki yönelme biçimbiriminin nesne üzerine taşındığı ve bundan ötürü de nesnedeki yükleme biçimbirimin boşaldığı/düştüğü görülür. Üçüncüsü, insan ile nesne arasındaki ilişki arttıkça insan-nesne ilişkisini belirten fiillerin tamlayıcıları da çoğalır ve değişir. Böylelikle fiille öznenin arası açılır, yani özne ile fiil arasına nesneler ve tümleçler girer. Fiil tamlayıcılarının -nesne ve tümleçlerin- sayısı ikiyi geçmeye başlayınca da tamlayıcıların birbiri üzerine taşınması söz konusu olur. Dildeki en az çaba yasası da bu taşınmayı destekler. Nitekim bin- fiilinin zamanla yönelme biçimbirimi ile kullanılmasında bu durum etkili olmuştur. Dördüncüsü hem yükleme hem yönelme biçimbirimini değiştiren $a l-$, at-, bağla-, dök-, götür-, sor- gibi bazı fiillerin asıl anlamları ile yüklemeyi kabul ederlerken anlam genişlemesi ve anlam değişmesi sonucunda yönelme biçimbirimini de tamlayıcı olarak almalarıdır. Sonuç olarak fiillerin kavram alanı ve bu kavram alanına sahip diğer fiillerle ilişkisi ve anlam yükü Manisa ağızlarında görülen $+(y) A /+(y) I / U$ değişiminde etkilidir. Ayrıca nesne ve tümleçlerdeki biçimbirimlerin birbiri üzerine taşınması ya da birleşmesi de bu değişimde önemli bir etmendir (2013, s. 641-646).

Demir, Güneybatı Anadolu ağızlarında Çuvaşçadaki gibi tek bir $+(y) A$ biçimbirimi olduğunu ve bunun hem yönelme hem belirtme işlevinde kullanıldığını ifade eder. Demir'e göre bu ağızlarda yönelme ve belirtme işlevinde kullanılan diğer biçimbirimler, $+(y) A^{\prime}$ nın altbiçimbirimleridir ve ses bilgisel sebeplerden dolayı ortaya çıkmıştır (2014, s. 144).

Özkan, Gagavuz Türkçesinde yönelme ve yükleme biçimbirimlerinin birbiri yerine kullanıldığına dikkat çeker. Özkan'a göre yönelme yerine yüklemenin görülmesi ses bilgisel bir durumdur. Komşu dar ünlünün ve yarı ünlü /y/ ünsüzünün darlaştırma etkisi ile $+(y) A$ biçimbirimin $+(y) I / U$ biçimbirime dönüştüğünü ifade eder. Özkan, yükleme yerine yönelme biçimbirimin kullanılmasını da yer yer karşılaşılan bir biçimbirim görev değişikliği olarak açıllar (1996, s. 125-126).

Karahan, fiil tamlayıcı ilişkisinin varlığını, şeklini ve niteliğini belirleyenlerin o dili kullananlar olduğunu dile getirir. Ona göre fiillerin tamlayıcılarındaki durum biçimbirimlerin lehçe ve ağızlara göre farklılık göstermesi, o dili kullananların tasavvurundaki farklılıklardan kaynaklanır (1997, s. 212). Özkan da fiil tamlayıcı ilişkisinin niteliğinin belirlenmesinde o dili konuşanların etkili olduğunu belirtir. Ayrıca Özkan'a göre fiilin anlamı da bu ilişkiyi belirlemede etkilidir (2011, s. 529).

Johanson dillerin, konuşuldukları bölgelerde baskın olan ikinci bir dilden etkilenebildiğini söyler ve bu durumu bir tür kod kopyalama olarak açılar (2007, s. 29). O, Türkiye Türkçesinde $+(y) A$ biçimbirimi isteyen bin- fiilinin bazı Türk lehçelerinde $+(y) I / U$ biçimbirimi ile kullanılmasını buna bağlar ve Rusçanın bu Türk lehçeleri üzerindeki etkisine dikkat çeker (2007, s. 33-35). Özkan da Gagavuz Türkçesinde durum biçimbirimlerde meydana gelen bazı değişimlerin baskın olan yabancı dilin etkisi ile ilgili olduğunu dile getirir (1996, s. 125-128). 
Yaman, Özbek Türkçesindeki durum biçimbirimlerinde meydana gelen değişimleri üç sebeple açıklar. Her dilin geçirdiği süreçlerin farklı olması ve dilin kullanımının o dili konuşurlarca belirlenmesi bu değişimlerin ilk sebebidir. Özbekçedeki bu değişimlerin ikinci sebebi, anlatım yollarının geliştirilmesi ihtiyacıdır. Karaca da Kazak Türkçesinde meydana gelen bazı değişimleri bu sebebe bağlar (2011, s. 29-32). Yaman'a göre bu değişmelerin üçüncü sebebi, diğer dillerin etkisidir (2000, s. 1918).

Tüm bu bilgilerden hareketle Türkçede $+(y) A /+(y) I / U$ değişiminin sebeplerini şu şekilde sıralamak mümkündür:

1. ET.nin $\mathrm{n}$ lehçesinde görülen $+A g$ belirtme biçimbiriminin ağızlarda devam etmesinden dolayı meydana gelen değişim.

2. Ses bilgisel sebeplerden dolayı meydana gelen değişim.

3. Aynı kavram alanına sahip fiillerin birbirinden etkilenmesinden dolayı meydana gelen değişim.

4. Derin yapıdan yüzey yapıya geçiş sırasında oluşan boşalmadan dolayı meydana gelen değişim.

5. Fiillerin tamlayıcılarının birbirinden etkilenmesinden dolayı meydana gelen değişim.

6. Fiillerin anlamlarının genişlemesi / değişmesinden dolayı meydana gelen değişim.

7. Durum biçimbirimlerindeki görev değişikliğinden dolayı meydana gelen değişim.

8. Dil kullanıcılarının tasavvurundaki farklılaşmadan dolayı meydana gelen değişim.

9. Yerel ya da baskın dillerden etkilenmeden dolayı meydana gelen değişim.

10. Dillerin geçirdiği süreçlerdeki farklılıklardan dolayı meydana gelen değişim.

11. Anlatım yollarını genişletme ihtiyacından dolayı meydana gelen değişim.

Sarıca da Türkçede $+(y) A /+(y) I / U$ değişikliğinin sebeplerini şu şeklide sıralar.

1. Fonetik sebepler.

2. Dilin ortaya çıkışında nesnelerin algılanışı ile kültürel değişmeler nedeniyle değişen durumlar.

3. Komşu dillerle etkileşimler.

4. Çevirilerde kaynak dilin ağırlık kazanması.

5. Fiillerin anlam değişikliklerine uğraması.

6. Şiirde kafiye ve ölçüden kaynaklanan durumlar.

7. Dil sürçmeleri, yetkin bir dilbilgisine sahip olamama, özensiz kullanımlar (2006, s. 217).

Türkçedeki $+(y) A /+(y) I / U$ değişimi için verilen bu sebepler, ayrıntılı olarak yapılan incelemeler sonucunda daha da artırılabilir. Peki, Oğuz grubu Türk lehçelerinde ${ }^{2}$ ortak olarak kullanılan act-, bak- döv-, gül- ve seyret- fiillerinin tamlayıcılarında meydana gelen $+(y) A /+(y) I / U$ değişimlerinin sebebi / sebepleri nelerdir? Yukarıda verilenler dışında başka sebepler de bu değişimlerde etkili olmuş mudur?

${ }^{2}$ Oğuz Grubu Türk lehçeleri hakkında ayrıntılı bilgi için bkz. Korkmaz 2013; Buran, vd. 2015. SEFAD, 2021; (45): 143-158 
Türkçede fiil tamlayıcılarındaki durum biçimbirim değişiklikleri zaman içerisinde gerçekleşir (Banguoğlu, 2015, s. 528; Özkan, 1999, s. 130). Özkan, fiil tamlayıcı ilişkisinde zaman içerisinde meydana gelen bu değişmeleri, bir lehçe veya bir ağız ile diğer lehçe veya ağız arasında bir işlev değişikliği gibi değerlendirmek yerine o lehçe veya ağız içinde değerlendirilmesi gerektiğini dile getirir (2011, s. 523). Biz de söz konusu değişikliklerin sebeplerini açıklama konusunda daha doğru bilgilere ulaşmak amaciyla her bir lehçenin kendi içerisinde değerlendirilmesi gerektiğini düşünmekteyiz. Dolayısıyla bu çalışmada söz konusu değişimlerin sebepleri her bir lehçe için ayrı ayrı değerlendirilmiştir.

Durum biçimbirimlerindeki değişimler, zaman içerisinde meydana geldiğine göre $a c l-$, bak- döv-, gül- ve seyret- fiillerinin, öncelikle Eski Anadolu Türkçesi (EAT) döneminde ve günümüzdeki Oğuz grubu Türk lehçelerinde, hangi durum biçimbirimlerle kullanıldığını vermek yerinde olacaktır. ${ }^{3}$

Tablo I. act-, bak- döv-, gül- ve seyret- Fiillerinin EAT / Osm. T. ve Ŏ̆uz Grubu Türk Lehçelerinde Durum Biçimbirimlerle Kullanımı

\begin{tabular}{|c|c|c|c|c|c|c|}
\hline FîiL & ANLAMI & $\begin{array}{l}\text { EAT } \\
\text { Osm. T. }\end{array}$ & TT. & Az. $T$. & Ggvz. T. & Trkm T. \\
\hline Act- & Merhamet etmek & $+(y) A$ & $+(y) A$ & $+(y) A$ & $+(y) I / U$ & - \\
\hline Bak- & $\begin{array}{l}\text { Gözetmek, } \\
\text { korumak. }\end{array}$ & $+(y) A$ & $+(y) A$ & $+(y) A$ & $+(y) I / U$ & $+(y) I / U$ \\
\hline Döv- & $\begin{array}{l}\text { Üst üste vurmak, } \\
\text { dayak atmak, darp } \\
\text { etmek }\end{array}$ & $+(y) I / U$ & $+(y) I / U$ & $\begin{array}{l}+(y) A \\
+(y) I / U\end{array}$ & $+(y) I / U$ & $+(y) I / U$ \\
\hline Gül- & Biriyle alay etmek & $+(y) A$ & $+(y) A$ & $+(y) A$ & $+(y) I / U$ & $+(y) A$ \\
\hline Seyret- & Bakmak, izlemek & $+(y) I / U$ & $+(y) I / U$ & $+(y) I / U$ & $+(y) I / U$ & $+(y) A$ \\
\hline
\end{tabular}

Bu çalışmada Oğuz grubu Türk lehçelerinde ortak olarak -aynı ya da yakın anlamdakullanılan act-, bak- döv-, gül- ve seyret- fiillerinin bu lehçelerde neden farklı tamlayıcılarla kullanıldığı açıklanmaya çalışılmıştır. Bu nedenleri açıklamak amacıyla fiillerin tarihsel süreç içerisinde hangi anlamlarda ve hangi tamlayıcılarla kullanıldığına değinilmiştir. Fiiller her bir lehçe içerisinde ayrı ayrı ele alınmıştır. Fiillerin anlamları ve tamlayıcılarını belirlemek amacıyla "Türkçe Sözlük" (TS), "Karşılaştırmalı Türk Lehçeleri Sözlüğü" (TLS) "Dîvânu Lugâti't-Türk" (DLT), Tarama Sözlüğü (TAS), Kâmûs-1 Türkî (KT), "17. Yüzyıl Türkçesi ve Söz Varlı̆̆ı" (TSV), Derleme Sözlüğü (DS) ve çeşitli yüksek lisans / doktora tezlerinden faydalanılmıştır.

\section{AZERBAYCAN TÜRKÇESI}

\subsection{Döv-}

Döv- fiili DLT'de tög- şeklinde ve "dövmek, inceltmek" anlamıla verilir (Atalay, 20013/ IV, s. 643). EAT döneminde sözcük başındaki tonsuz /t/ fonemi tonlulaşır. Fiil bu dönemde dög-şeklinde ve "dövmek, vurmak" anlamında +(y)I/U biçimbirimli tamlayıcı ile kullanılır (Ergin, 2018, s. 2008). Bu kullanım günümüz Oğuz grubu Türk lehçelerinde de devam etmektedir (TS, s. 718-719, Özdemir, 2012, s. 85, Uzunsoy, 2008, s. 55)

\footnotetext{
${ }^{3}$ Horasan Türkçesi günümüzde yazılı bir dile sahip değildir. Dolayısıyla bu çalışmaya dahil edilmemiş ve Tablo I'de gösterilmemiştir. Ayrıca fiillerin tabloda verilen anlamları ile kullanımı EAT.de tespit edilemediği durumlarda Osmanlı Türkçesi (Osm. T.) örnekleri esas alınmıştır.
} 
Az. T.de döv- fiili, sıklıkla $+(\mathrm{y}) \mathrm{I} / \mathrm{U}$ biçimbirimli tamlayıcı ile kullanılmasına rağmen bazen $+(y) A$ biçimbirimli tamlayıcı ile kullanımı da görülür.

A1: (O) damiri döydü. “O demiri dövdü.” (Çiçekli, 2013, s. 216-217)

A2: Bark qorxdu, başına döyüb ağladı, bildi ki, onu dev oğurlayıb gatirmişdir. "Çok korkmuş, başını dövüp ağlamış, onu devin kaçırıp getirdiğini anlamış." (Dura, 2017, s. 37).

Görüldügü üzere döv- (döy-) fiili, A1'de +(y)I/U biçimbirimli, A2' de $+(y) A$ biçimbirimli tamlayıcı istemektedir. A2' de yer alan başına döy- fiili Az. T.de deyim olarak kullanılır. TT.de bu deyim dizini döv-fiili ile karşılanır.

Deyimler genellikle anlatım yollarını geliştimek amacıyla ortaya çıkan, gerçek anlamından farklı mecazi bir anlam bildiren kalıplaşmış söz birlikleridir. Yaman, anlatım yollarının geliştirilmesi ihtiyacını, fiil tamlayıcı ilişkisinde meydana gelen farklılaşmaların bir sebebi olarak görür. $\mathrm{O}$, bu tür yapıların kendiliğinden ortaya çıktı̆̆ını, çünkü, böyle yapıların çoğunlukla ikincil, mecazi anlamlar bildirdiğini belirtir (2000, s. 1918). Az. T.de kullanılan başına döy-fiilindeki tamlayıcının farklı kullanılması da bu durumla ilgilidir.

\section{GAGAVUZ TÜRKÇESİ}

\subsection{AC1-}

Acı- fiili Eski Türkçede açı- şeklinde ve "acımak, ekşimek" anlamında kullanılmıştır (Gabain, 2000, s. 258). Bu anlamıla ET.de cansız varlıklar için kullanılan eylem DLT'de ayrıca "yara, vücut acımak" anlamıla canlı varlıklar için de kullanılır olmuştur (Atalay, 2013/IV, s. 2). EAT.de söz ortasındaki /ç/ foneminin tonlulaşması sonucu fiil, bugünkü aclşeklini almıştır. Bu dönemde ayrıca fiilde semantik bir değişim söz konusudur. Fiil, TAS'da "eziyet görmek, canı yanmak" anlamındadır (2009, s. 5).

Osm. T. döneminde fiilin anlamında ciddi bir genişleme görülür. Tulum, act- fiili için beş farklı anlam verir. 1. Dert çekmek. 2. İncinmek, gocunmak. 3. Merhamet etmek. 4. Ağlamak. 5. Şikâyet etmek. (2011, s. 246). Şemseddin Sami de KT'de fiilin üç farklı anlamda kullanıldığını belirtir. 1. Ağrımak. 2. Keder ve teessüf etmek, merhamete gelmek. 3. Esirgemek, kıyamamak. Şemseddin Sami, act- fiilinin "merhamet etmek" anlamı için "şu adamın hâline actrım." örneğini verir (2018, s. 27). Görüldüğü üzere bu dönemde act- fiili "merhamet etmek" anlamında $+(y) A$ biçimbirimli tamlayıcı istemektedir. Fiilin bu anlamda $+(y) A$ biçimbirimle kullanılmasında merhamet et- fiilinin etkisi büyüktür.

Merhamet et- / kıl- fiili EAT.de $+(y) A$ biçimbirimi ile kullanılmıştır.

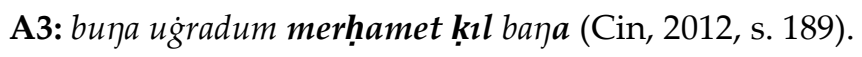

$\mathrm{KT}^{\prime}$ de de fukaraya merhamet et- örneği ile verilen bu fiilin $+(y) A$ biçimbirimi ile kullanıldığı görülür. Act- fiili, merhamet et- fiili ile aynı kavram alanına sahiptir. Dolayısıyla söz konusu fiil, yeni bir anlam kazandığında, aynı kavram alanındaki merhamet et- fiilinden etkilenerek $+(y) A$ biçimbirim ile kullanılır olmuştur. Act- fiili günümüzde bu anlamı ile TT.de de $+(y) A$ biçimbirim ile kullanılır.

A4: Yarını ne olacak dünyamızın / Biz yaşımızı başımızı aldık / Allah çocuklarımıza acısın. (TS, s. 11) 
Ggvz. T.de fiil, "merhamet etmek" anlamında $+(y) I / U$ biçimbirim ile kullanılır. Özkan bu durumu komşu dar ünlü ya da yarı ünlü /y/ foneminin etkisi ile ortaya çıtığı düşünülen bir görev değişikliği olarak tanımlar ve şu örnekleri verir (1996, s. 125-126).

A5: Sändän kaari kim beni acıyacak "Senden başka kim bana acıyacak!"

A6: Acısa onu Alla "Allah ona acisa."

Özkan'a göre bu durum ses bilgisel bir değişiklikten dolayıdır ancak, verilen örneklerde ses bilgisel bir değişim söz konusu değildir. A5'teki ben zamirinde ve A6'daki $o$ (n) zamirinde ne dar bir ünlü ne de daraltıcı etkiye sahip bir /y/ fonemi vardır.

Karabulut ve Özdemir, acl- fiilinde görülen bu farklı kullanımın fiilin istemi ile ilgili olduğunu dile getirirler. Onlar bu durumun sebebini söz konusu fiilin geniş ünlü yerine dar ünlülü bir tamlayıcıyı tercih etmesine bağlarlar (2017, s. 105).

Özakdağ Ggvz. T.de act- fiilinin tamlayıcısında meydana gelen biçimbirim değişikliğini Rusçanın etkisine bağlar ve şu örneği verir.

A7: Sän acıma ne kendini, ne beygirini. "Sen ne kendine ne beygirine ac1."

Özakdağ, A7'de hem ögelerin siralanışında $(\ddot{O}+Y+N)$ hem ne...ne olumsuzluk edatlarıyla kurulan cümlenin yükleminin olumsuz olmasında hem de tamlayıcıların durum biçimbirimlerinin $+(y) I / U$ olmasında Rusçanın etkili olduğunu belirtir (2016, s. 200).

Her ne kadar bu durum, Özakdağ tarafından Rusçanın etkisi olarak, Karabulut ve Özdemir tarafından da istem ile ilgili bir durum olarak açıklansa da bu değişimin başka sebepleri de olabilir. Demirci fiillerdeki istem değişmelerinin birden fazla sebebi olabileceğini ifade eder (2007, s. 138-139). Bize göre act- fiilinin $+(y) I / U$ biçimbirim ile kullanılması, yeni bir anlam kazanması ile ilgilidir. Ggvz. T.de act- fiilinin temel anlamı DLT'de olduğu gibi “Ağrı duymak"tır. (Özdemir, 2012, s. 120). Dolayısıyla fiilin bu anlamı daha eski görünmektedir. İlerleyen süreçte bu lehçede yeni bir anlam kazanan fiil, bu anlamı ile yeni bir tamlayıcıya ihtiyaç duymuş ve bu ihtiyacı $+(y) I / U$ biçimbirim alan bir tamlayıcı ile gidermiştir. Mezkûr fiille ilgili benzer bir durum Anadolu ağızlarında da görülür.

TT.de act- fiili 1. Tadı acı duruma gelmek, acılaşmak. 2. Acılı, ağrılı olmak. anlamları ile tamlayıcısız -sadece özne ile- kullanılır. Fiil, 1. Merhamet etmek. 2. Başkasının uğradığı veya uğrayacağı kötü bir duruma üzülmek. anlamları ile $+(y) A$ biçimbirimli tamlayıcı ile kullanılır (TS, s. 11). Anadolu ağızlarında TT.den farklı olarak fiilin bir de "Sevmek, okşamak" anlamı vardır. (DS, s. 50). Ağızlarda bu anlamıyla fiil, +(y)I/U biçimbirimli tamlayıc ile kullanılır.

A8: Gel evladım seni acıyayım. "Gel evladım seni seveyim." (DS: 50)

Ggvz. T.de olduğu gibi Anadolu ağızlarında da act- fiilinde meydana gelen anlam değişimi, fiilin tamlayıcısında da bir değişime sebep olmuştur.

\subsection{Bak-}

Bak- fiili DLT'de "Bakışı bir şey üzerine çevirmek" anlamında ve $+(y A)$ biçimbirim ile kullanılmıştır (Atalay, 2013/II, s. 16). EAT.de fiilde fonetik olarak bir değişiklik olsa da semantik olarak bir değişim söz konusu değildir. Fiil bazen bu dönem eserlerinde bahşeklindedir (TAS, s. 379). 

Durum Biçimbirimlerinin Farklı Kullanımı: Act-, Bak- Döv-, Gül-ve Seyret- Fiilleri Örneğg

Osm. T. döneminde fiilin anlamında ciddi bir genişleme görülür. Tulum, TSV'de fiilin 1. Nazar etmek. 2. Mütalaa etmek. 3. Görmek. 4. Muayene etmek. 5. Seyretmek, temaşa etmek. 6. Göz dikmek. 7. Gözlemek, gözetmek. 8. Riayet etmek. 9. İltifat etmek. olmak üzere dokuz farklı anlamını verir (2011, s. 361). Şemseddin Sami KT'de bak- fiili için on iki farklı anlam verir. Tulum'dan farklı olarak KT'de fiilin 1. Hizmetini görmek. 2. İaşe ve infak etmek, beslemek, geçindirmek. 3. (hastayı) ziyaret etmek. anlamları yer alır. KT'de verilen örneklere göre söz konusu fiil, "Dikkat ve itina etmek, gözleri açmak" anlamında $+\varnothing$ biçimbirimli tamlayıcı, diğer bütün anlamlarda -“Gözetmek, korumak, kollamak, beslemek, yetiştirmek" anlamı da dahil- +(y)A biçimbirimli tamlayıcı ile kullanılır (KT, s. 214).

Bak- fiili Osm. T.de olduğu gibi günümüzde TT.de de “Gözetmek, korumak, kollamak, beslemek, büyütmek, yetiştirmek" anlamında $+(y) A$ biçimbirimli tamlayıcı ile kullanilır.

A9: Üç çocuklu bir aileye bakıyor (TS, s. 240).

Ggvz. T.de bak- fiilinin temel anlamı "Bakışı bir şey üzerine çevirmek"tir. Fiil bu anlamıyla kullanıldığında $+(y) A$ biçimbirimli tamlayıcı istemektedir. Ancak bu anlamda $+(y) I / U$ biçimbirimli tamlayıcı ile kullanılan örnekler de mevcuttur.

A10: Bakın burayı. "Bakın buraya" (Özdemir, 2012, s. 74).

A10'da bak- fiili $+(\mathrm{y}) \mathrm{I} / \mathrm{U}$ biçimbirim ile kullanılmıştır. Ancak bu durum fonetik bir hadisedir. "burayı" sözcügündeki daraltıcı etkiye sahip /y/ fonemi, /a/ fonemini darlaştırarak /1/ fonemine dönüştürmüştür. Ggvz. T.de bu değişim budalayı < budalaya, nereyi < nereye vb. örneklerde de görülür (Özkan, 1996, s. 126). Dolayısıyla bu değişimin geçici olduğu ve esas kullanımın $+(y) A$ biçimbirimli tamlayıcı ile yapıldığı söylenebilir.

"Gözetmek, korumak, kollamak, beslemek, büyütmek, yetiştirmek" anlamı daha geç bir dönemde ortaya çıkn bak- fiili bu anlamı ile Ggvz T.de +(y)I/U biçimbirimli tamlayıcı istemektedir. Burada fiilin anlamıyla birlikte tamlayıcısında da bir değişim söz konusudur.

A11: O sade kendi kızlarını bakar. “O sadece kendi kızlarına bakar” (Özkan, 1996, s. 126).

Bu değişimde bak- fiili ile aynı kavram alanında yer alan kolla- fiili de etkili olmuştur. Kolla- fiili Ggvz. T.de +(y)I/U biçimbirimli tamlayıcı ile kullanılır (Özdemir, 2012, s. 99).

\subsection{Gül-}

Gül- fiili DLT'de "Kesik kesik sesler çıkarmak suretiyle duygusunu, sevinç veya hayretini açığa vurmak" temel anlamıyla kül- şeklinde kullanılmıştır (Atalay, 2013 /II, s. 395). EAT.de sözcük başındaki tonsuz / $/ \mathrm{k}$ foneminin tonlulaşması sonucu fiil bugünkü gül-şeklini almıştır. Bu dönemde fiil temel anlamıyla tamlayıcısız -özne + (zarf tümleci) + yüklemolarak kullanılmıştır.

A12: anı țuydum güldüm ilkin sevinü (Y1ldız, 2008, s. 276).

A13: Kas kas güldüñ. (Emre, 2008, s. 121).

EAT döneminde gül- fiili temel anlamının yanı sıra yeni bir anlam daha kazanmıştır. "Biriyle /bir şeyle alay etmek." Bu anlamıyla fiil, cümle içerisinde yeni bir tamlayıcıya ihtiyaç duymuş ve bu ihtiyacı $+(y) A$ biçimbirimli tamlayıcı ile gidermiştir.

SEFAD, 2021; (45): 143-158 
Gülme sakın sen aña eyü degildür saña (Tatçı, 1990, s. 628).

Günümüzde gül- fiili TT.de de "Biriyle alay etmek" anlamında kullanıldığında $+(y) A$ biçimbirimli tamlayıcı istemektedir.

A14: Gülme komşuna gelir başına.

Ggvz. T.de gül- fiili "Biriyle /bir şeyle alay etmek" anlamında kullanıldığında diğer Oğuz grubu Türk lehçelerinden farklı olarak $+(y) I / U$ biçimbirimli tamlayıcı istemektedir (Özdemir, 2012, s. 129).

Sän da mi gülersin beni be? "Sende mi bana gülüyorsun be?" (Özdemir, 2012, s. 129).

Mezkûr fiilin söz konusu anlamda $+(y) I / U$ biçimbirimli tamlayıcı ile kullanımı Anadolu ağızlarında da görülür.

A15: Babasını kak kak gülsün (Caferoğlu, 1962, s. 113).

Ağızlarda görülen bu kullanımın, bir ağız özelliği olduğu veyahut kaynak kişi ya da kişilerin tasavvurundaki farklılaşmadan dolayı meydana geldiği söylenebilir. Böylece insan zihninde (derin yapıda) $+(y) A$ biçimbirimli tamlayıcı ile kodlanan gül- fiili, kaynak kişi tarafından yüzey yapıya $+(y) I / U$ biçimbirimli tamlayıcı ile çıkartılır. Nitekim Anadolu ağızlarında gül- fiilinin TT.de olduğu gibi $+(y) A$ biçimbirimli tamlayıcı ile kullanıldığı örnekler de mevcuttur.

A16: Amı dünya bize güldü. "Herkes bize güldü” (DS, s. 239).

Ggvz. T.de de fiilin farklı bir tamlayıcı ile $(+(y) I / U)$ kullanılmasında o dili kullanan kişilerin tasavvurundaki farklılaşma önemli bir etmendir. Ayrıca, bu lehçede fiillerin farklı bir tamlayıcı ile kullanılmasında yabancı dil(ler)in de önemli bir etkisi (Slav dilleri) vardır.

\section{TÜRKMEN TÜRKÇESİ}

\subsection{Bak-}

Trkm. T.de bak- fiilinin temel anlamı "Birini ya da bir zatı seyretmek", ikinci anlamı "gözetmek, yetiştirmek, büyütmek"tir. Fiil temel anlamda $+(y) A$ biçimbirimli tamlayıcı ile diğer anlamda ise $+(y) I / U$ biçimbirimli tamlayıcı ile kullanılır. (Baytürk, 2015, s. 65).

A17: Şofyor-yaş yiğit-de, yolağçı giz da kabinadan giň meydana bakyardı. "Şoför, genç delikanlı da yolcu kız da kabinden geniş ovaya bakıyordu."

A18: Oları çekdirme bilen bakdı. "Onları et yemekleri ile büyüttü." (Erdem, 2004, s. 943944)

Melek Erdem bu durumu, fiilin anlam değişmesine bağlar ve anlamla birlikte tamlayıcıdaki durum biçimbirimin de değiştiğini ifade eder (2004, s. 944). Bize göre bu değişimin bir diğer sebebi aynı kavram alanına sahip besle-, tayyarla-, ekle-, terbiyele-, gora-, idet- vb. fiillerin etkisidir. Trkm. T.de söz konusu fiiller "Gözetmek, korumak, kollamak, beslemek, büyütmek, yetiştirmek" anlamında $+(y) I / U$ biçimbirimi ile kullanılır.

\subsection{Seyret-}

Arapça seyr "yürüme, yürüyüş" ve Türkçe et- fiilinin birleşimi sonucu oluşan (seyr+et>) seyret- fiili EAT.de "Gezinmek, dolaşmak" anlamındadır (Yıldız, 2008, s. 480). 

Durum Biçimbirimlerinin Farklı Kullanımı: Act-, Bak-Döv-, Gül-ve Seyret- Fiilleri Örneğg

Osm. T. döneminde seyret- fiilinin anlamında bir genişleme söz konusudur. Tulum TSV'da fiilin dört farklı anlamını verir. 1. Bakmak. 2. Mütalaa etmek. 3. Gezmek, gezinmek. 4. Salik olmak. (2011, s. 1584) KT'de de fiil bu anlamları ile verilmiştir. Şemseddin Sami, seyret- fiilinin "Bakmak" anlamı için "bahçeyi, çarşıyı, hayvanatı, yeni gelen eşyayı seyretmek" örneğini verir (KT, s. 591). Görüldüğü üzere seyret- fiili, Osm. T. döneminde "bakmak" anlamında kullanıldığında $+(y) I / U$ biçimbirimli tamlayıcı istemektedir.

Fiil günümüzde TT.de de "Bakmak" anlamında $+(y) I / U$ biçimbirimli tamlayıcı ile kullanilır (TS, s. 2084).

A19: Rabia biraz şaşkın, salapuryada arkadaş olduğu çocuklu tazenin kocasıyla buluşmasını seyrediyordu. (TS, s. 240).

Türkm. T.de seyret- fiili "Bakmak" anlamında kullanıldığında $+(y) A$ biçimbirimli tamlayıcı istemektedir.

A20: $\mathrm{Ol}$ şol tekepbir garayşı bilen adamlara seretdi. "O kibirli bakışı ile şu adamları seyretti." (Baytürk, 2015, s. 397)

Bak- fiili seyret- fiili ile ayn kavram alanına sahiptir. Dolayısıyla Türkm. T.de fiilin $+(y) A$ biçimbirimli tamlayıcı ile kullanılmasında bak- fiili etkili olmuştur. Türkm. T.de bakfiili "Seyretmek" anlamında $+(y) A$ biçimbirim ile kullanılır (Baytürk, 2015, s. 65).

\section{SONUÇ}

Türk lehçelerinde ve Anadolu ağızlarında -özellikle güneybatı Anadolu ağızlarındagörülen yönelme ve belirtme biçimbirim değişikliği, Oğuz grubu Türk lehçelerinde de görülür. Bu lehçelerde ortak olarak -aynı ya da yakın anlamda- kullanılan acl-, bak-, döv-, gülve seyret- fiilleri farklı tamlayıcılar ile kullanılmıştır. Söz konusu fiillerin farklı tamlayıcalar ile kullanılmasının sebepleri şu şekilde sıralanabilir:

1. Fiilin yeni bir anlam kazanması sonucu yeni bir tamlayıcaya ihtiyaç duyması ya da anlam ile birlikte tamlayıcının da değişmesi. (acl-, döv-, bak-)

2. Fiilin aynı kavram alanına sahip diğer fiillerinden etkilenmesi sonucu meydana gelen değişim. (bak-, seyret-)

3. Fiilin yabancı dilden / dillerden etkilenmesi sonucu meydana gelen değişim. (actgül-)

4. Kaynak kişinin tasavvurundaki farklılaşmadan dolayı meydana gelen değişim. (gül)

5. Anlatım yollarını genişletme / geliştirme ihtiyacından dolayı meydana gelen değişim. (döv-)

Şive ya da lehçeler arasındaki farklılaşma büyük oranda fonetik düzeydedir. Fonetik düzeydeki farklılaşmanın yanı sıra morfolojik düzeyde farklılaşmalar da görülür. Ancak söz dizimsel düzeyde farklılaşma oldukça azdır. Oğuz grubu Türk lehçelerinde görülen $+(y) A$ / $+(y) I / U$ durum biçimbirim farklılaşması söz dizimsel istem ile ilgilidir. TT. ile kıyaslandığında bu farklılaşmanın en çok görüldüğü lehçe Ggvz. TT.dir.

Ggvz. T., Oğuz Türkçesinin ayrı bir kolu olarak Hazar denizinin kuzeyinde Oğuz kafilesinden ayrılan Türk boylarının ilerledikleri coğrafya boyunca Bulgar ve Kıpçak Türkçesi unsurları ile karışmışır. Selçuklular ve Osmanlılar vasıtasıyla da Anadolu 
Türkçesinden etkilenmiş, birçok Arapça ve Farsça kelimeyi söz varlığına katmıştır. Bu sebeple Ggvz. T. bir tafaftan EAT.ye bir taraftan da Bulgar ve Kıpçak Türkçelerine yakınlık gösterir. Romen, Rus ve Yunan dillerinden de etkilenmiş, böylelikle Oğuz Türkçesinden ses ve söz dizimi bakımından farklılaşmıştır. Bu etkileşimler dolayısıyla TT. ile kıyaslandığında Ggvz. T.de daha fazla $+(y) A /+(y) I / U$ değişiminin görülmesi beklenen bir durumdur.

Tespit edilen örneklere göre Ggvz. T.de daha çok yönelme yerine belirtme biçimbirimi kullanılır. Bu kullanımın sıklıkla zamirler üzerinde görülmesi dikkat çekicidir. Benzer bir durum Güneybatı Anadolu ağızlarında da vardır. Bu ağızlarda özellikle ben kişi zamiri bana şeklinde değil beni şeklinde kullanılır. Beni bir cay yap.

Türk lehçelerinde yönelme ve belirtme biçimbirimlerinin karışık kullanımı, araştırmacıların nesne kavramı üzerinde düşünmelerine sebep olmuştur. Herhangi bir fiilin ortak olarak -aynı ya da yakın anlamda- bir lehçede $+(y) A$, bir lehçede $+(y) I / U$ biçimbirimli tamlayıc ile kullanılması "Cümlenin nesnesi nasıl belirlenmelidir?, Cümlede nesne belirlenirken hangi ölçütler esas alınmalıdır?" gibi soruların yeniden cevaplanması gerektiğini ortaya koymuştur. Örneğin bak- fiili "Gözetmek, korumak, kollamak, beslemek, yetiştirmek" anlamında TT. ve Az. T.de $+(y) A$ biçimbirimli tamlayıcı ile Trkm. T. ve Ggvz. T.de $+(y) I / U$ biçimbirimli tamlayıcı ile kullanılır. Bu durumda bak- fiilinin tamlayıcısı için Ggvz. T. ve Trkm. T.de belirli / belirtili nesne, TT. ve Az. T.de de yer tamlayıcısı / dolaylı tümleç demek doğru mudur?

Nesne, öznenin yaptığı işten etkilenen kişi ya da şeydir. Türkçede nesne kavramı biçim bilimsel bir yaklaşımla değil anlam bilimsel bir yaklaşımla ele alınmalıdır. Bak- fiilinin tamlayıcısı, üzerine aldığı biçimbirime bakılmaksızın eylemden etkilenendir. Dolayısıyla bu tamlayıcı hangi biçimbirimle kullanıldığına bakılmaksızın cümlenin nesnesi olarak değerlendirmelidir.

\section{SUMMARY}

There are many studies about the relationship between the situation suffixes and verbs in Turkish. The researchers brought different perspectives on this subject by giving examples from historical and contemporary Turkish languages. Recently, this subject has been addressed in studies on the valency.

In Turkish, the morphological changes of the verb complements occur over time. These changes that occur in the verb-complement relationship over time should be evaluated in that idiom or dialect, rather than as a function change between a dialect or an idiom and another dialect.

In this study, it is attempted to explain why the verbs ac1-, bak- gül-, döv- and seyretwhich are commonly -in the same sense- used in Turkish dialects of Oghuz group are used with different complements in these dialects. In order to explain these reasons, it has been mentioned in which meanings and with which complements verbs are used in the historical process. Verbs are discussed separately within each dialect. To determine the meanings and complements of verbs "Türkçe Sözlük" (TS), "Karşılaştırmalı Türk Lehçeleri Sözlüğü" (TLS) "Dîvânu Lugâti't-Türk" (DLT), Tarama Sözlüğü (TAS), Kâmûs-1 Türkî (KT), "17. Yüzyıl Türkçesi ve Söz Varlığı (TSV), Derleme Sözlüğü (DS) and various master's / doctoral theses were used. 

Durum Biçimbirimlerinin Farkh Kullanımı: Acı-, Bak-Döv-, Gül-ve Seyret- Fiilleri Örne ğ

The change of accusative and dative morpheme seen in Turkish dialects and Anatolian dialects, especially in southwestern Anatolian dialects, is also seen in Oghuz Turkish dialects. In these dialects, the common verbs ac1-, bak-, döv-, gül- and seyret-, which are used in the same sense, are used with different complements. The causes of using these verbs with different complements can be listed as follows:

1. The verb needs a new complement or the complement changes with the meaning, as a result of gaining a new meaning. (ac1-, döv- bak-)

2. The change that occurs as a result of the verb being affected by other verbs with the same conceptual area. (bak-, seyret-)

3. The change that occurs as a result of the verb being affected by foreign languages. (ac1-, gül-)

4. The change that occurs due to the differentiation in the source person's imagination. (gül-)

5. Emerging change due to the need to expand / improve the ways of expression. (döv-)

The mixed use of accusative and dative morphologies in Turkish dialects has caused researchers to consider the concept of object. Using any verb in the same sense with $+(y) A$ in a dialect and $+(\mathrm{y}) \mathrm{I} / \mathrm{U}$ in a dialect "How should the object of the sentence be determined? What criteria should be taken as basis when determining the object in the sentence?" revealed that these questions needs to be answered again.

Makale Bilgileri

\begin{tabular}{|c|c|}
\hline Etik Kurul Kararı: & Etik Kurul Kararından muaftır. \\
\hline Katılımcı Rızası: & Katılımcı Yok \\
\hline Mali Destek: & $\begin{array}{l}\text { Çalışma için herhangi bir kurum ve projeden mali destek } \\
\text { alınmamıştır. }\end{array}$ \\
\hline Çıkar Çatışması: & $\begin{array}{l}\text { Çalışmada kişiler ve kurumlar arası çıkar çatışması } \\
\text { bulunmamaktadır. }\end{array}$ \\
\hline $\begin{array}{l}\text { Telif Haklart: } \\
\text { Article Information }\end{array}$ & Telif hakkına sebep olacak bir materyal kullanılmamıştır. \\
\hline Ethics Committee Approval: & It is exempt from the Ethics Committee Approval. \\
\hline Informed Consent: & No participant \\
\hline Financial Support: & No financial support from any institution or Project \\
\hline Conflict of Interest: & No conflict of interest. \\
\hline Copyrights: & No material subject to copyright is included. \\
\hline
\end{tabular}




\section{KAYNAKÇA}

Acar, D. (2005). Die syntaktische valenz deutscher und Türkischer verben und ihr einfluss auf das deutschlernen türkischer studierender Aalmanca ve Türkçe fiillerde sözdizimsel birleşim değeri ve almanca öğrenimine yansıması). (Yüksek Lisans Tezi). Erişim adresi: https://tez.yok.gov.tr/UlusalTezMerkezi/giris.jsp.

Arı Özdemir, T. (2012). Gagavuz Türkçesinde istem. (Yüksek Lisans Tezi). Erişim adresi: https://tez.yok.gov.tr/UlusalTezMerkezi/giris.jsp.

Arı, N. (2010). Harezm Türkçesinde birleşik fiiller ve durum ekli tamlayıcıları. (Yüksek Lisans Tezi). Erişim adresi: https://tez.yok.gov.tr/UlusalTezMerkezi/giris.jsp.

Atacık, D. A. (2008). Türkiye Türkçesinde istem (Valenz). (Yüksek Lisans Tezi). Erişim adresi: https://tez.yok.gov.tr/UlusalTezMerkezi/giris.jsp.

Aydın Özkan, I. (2018). Evrensel dil bilgisi ve Türkçede istem. Ankara: Gece Kitaplığı.

Banguoğlu, T. (2015). Türkçenin grameri. Ankara: TDK Yayınları.

Baytürk, F. (2015). Türkmen Türkçesinde fiillerin istemi. (Yüksek Lisans Tezi). Erişim adresi: https://tez.yok.gov.tr/UlusalTezMerkezi/giris.jsp.

Bilveren, T. (2015). Özbekçe ve Türkiye Türkçesinde fiil - tamlayıcı ilişkisi. Türkish Studies, 10(8), 669-680. doi: 10.7827/TurkishStudies.8184

Buran, A. (1996). Anadolu ağızlarında isim çekim (hâl) ekleri. Ankara: TDK Yayınları.

Buran, A., Alkaya, E., Yalçın, S. K. (2015). Çağdaş Türk yazı dilleri 1, güney batı / Oğuz grubu. Ankara: Akçă̆ Yayınları.

Caferoğlu, A. (1962). Muğla ağzı. Türk Dili Araştırmaları Yıllığı-Belleten, 10(1), 107-130.

Cin, A. (2012). Süheyl ü Nev-Bahār (Kenzü’l Bedāȳi) inceleme-metin-dizin. Konya: Eğitim Kitabevi.

Çiçekli, H. (2013). Azerbaycan Türkçesinde fiillerin istemi. (Yüksek Lisans Tezi). Erişim adresi: https://tez.yok.gov.tr/UlusalTezMerkezi/giris.jsp.

Demir, İ. (2014). Türkçede belirtme-yönelme hâli ekleri ve güneybatı Anadolu ağızlarındaki kullanımları. Sosyal Bilimler Dergisi, 16(1), 129-147. Erişim adresi: https://sbd.aku.edu.tr/arsiv/c16s1/c16s1b7imdatdemir.pdf.

Demirci, K. (2007). Türkçede hâl eki nöbetleşmeleri üzerine. Karaman Dil-Kültür ve Sanat Dergisi, 126-139. Erişim adresi: https://www.academia.edu/10369174/t\%c3\%9crk\%c3\%87edek\%c4\%b0_hâl_ek\%c4\%b0_ n\%c3\%96betle\%c5\%9emeler\%c4\%b0_\%c3\%9czer\%c4\%b0ne.

Demirez Güneri, A. (2007). Yeni Uygur Türkçesindeki fiillerin durum ekli tamlayıcıları. (Doktora Tezi). Erişim adresi: https://tez.yok.gov.tr/UlusalTezMerkezi/giris.jsp.

Dinar, T. (2010). Kül Tigin abidesi ve Kutadgu Bilig'deki ortak fiillerin tamlayıcı ilişkisi açısından incelenmesi. Türkish Studies, 5(3), 1044-1091. doi: 10.7827/TurkishStudies.1562

Doğan, N. (2011). Türkiye Türkçesi fiillerinde isteme göre anlam değişiklikleri. (Doktora Tezi). Erişim adresi: https://tez.yok.gov.tr/UlusalTezMerkezi/giris.jsp.

Dura, F. (2017). Azerbaycan Türkçesinden Türkiye Türkçesine aktarma Sorunları. (Yüksek Lisans Tezi). Erişim adresi: https://tez.yok.gov.tr/UlusalTezMerkezi/giris.jsp.

Emre, V. (2008). Dede Korkut hikâyelerindeki fiillerin birleşim değerleri. (Yüksek Lisans Tezi). Erişim adresi: https://tez.yok.gov.tr/UlusalTezMerkezi/giris.jsp. 

Durum Biçimbirimlerinin Farklı Kullanımı: Act-, Bak-Döv-, Gül-ve Seyret- Fiilleri Örneğg

Ercilasun, A. B. (Ed.). (1991). Karşılaştırmalı Türk lehçeleri sözlü̈̆̈̈ (C. 1-2). Ankara: Kültür ve Turizm Bakanlığı Yayınları.

Erdem, M. (2004). Türkmen Türkçesinde mental fiillerin 'istem'e göre anlam değişmeleri. $V$. Uluslararası Türk Dili Kurultayı Bildirileri (C. 1), Ankara: TDK Yayınları, 939-950.

Erdem, M. (2006). Türkmen Türkçesinde hareket fiillerinin istem'e göre anlam değişmeleri. Modern Türklük Araştırmaları Dergisi, 2, 38-50. Erişim adresi: https://docplayer.biz.tr/152614807-Turkmen-turkcesinde-hareket-fiillerinin-istem-e-gore anlam-degismeleri.html.

Ergin, M. (2018). Dede Korkut Kitabı (C. 1-2). Ankara: TDK Yayınları.

Gabain, A. (2000). Eski Türkçenin grameri (Çev. Mehmet Akalın). Ankara: Türk Dil Kurumu Yayınları.

Gülsevin, G. (2002). Uşak İli Ağızları (dil özellikleri-metinlersözlük). Ankara: TDK Yayınları.

Günay, T. (2003). Rize ili ağızları (inceleme-metinler-sözlük). Ankara: TDK Yayınları.

İlker, A. (2013). Ağız alanlarında yükleme ve yönelme eklerinin birbiriyle değişme sebepleri üzerine. Leyla Karahan Armağanı, Ülkü Gürsoy (Haz.). Ankara: Akçağ Yayınları, 633-649.

Johanson, L. (2007). Türkçe dil ilişkilerinde yapısal etkenler (Çev. Nurettin Demir). Ankara: TDK Yayınları.

Kahraman, T. (1996). Çă̆daş Türkiye Türkçesindeki fiillerin durum ekli tamlayıcıları. Ankara: TDK Yayınları.

Karabulut, F., Arı Özdemir, T. (2017). İstem ve istem analizi: Gagauz Türkçesi ve Türkiye Türkçesi karşılaştırmalı bir çalışma. Dil Araştırmlaraı Uluslararası Hakemli Dergi. 21, 91112. Erişim adresi: http://www.dilarastirmalari.com/arsiv/sayi21/21\%20Sayi_Guz_2017_ICLER.pdf

Karaca, O. S. (2011). Kazak Türkçesinde fiil istemleri. İstanbul: Kesit Yayınları.

Karahan, L. (1997). Fiil-tamlayıcı ilişkisi üzerine. E. Arıkoğlu-D. Ergönenç Akbaba (Haz.), Türk Dili üzerine incelemeler içinde (s. 249-253). Ankara: Akçă̆ Yayınları.

Kaşgarlı M. (2013). Divanü Lûgat-it Türk (C. 1-2). Besim Atalay (Haz.) Ankara: TDK Yayınları.

Kaya,Y. (2007). Olmak fiiliyle yapılan birleşik fiiller ve tamlayıcılarla kullanılışı. (Yüksek Lisans Tezi). Erişim adresi: https://tez.yok.gov.tr/UlusalTezMerkezi/giris.jsp.

Korkmaz, Z. (1980). Batı Anadolu Ağızlarında yazı dilinden ayrılan isim çekimi ekleri ve fonologie-morphologie bağlantısı. Birinci Milli Türkoloji Kongresi, İstanbul.

Ölker, P. (2018). Eski Oğuz Türkçesinden klâsik Osmanlı Türkçesine birleşik fiil tercihi: Kabusname çevirisi örneği. Selçuk Üniversitesi Türkiyat Araştırmaları Dergisi, 43, 47-64. doi: https://doi.org/10.21563/sutad.447216

Özakdağ, N. (2016). Gagauz Türkçesinden Türkiye Türkçesine yapılan aktarmalarda karşılaşılan bazı sorunlar. Hamdullah Suphi ve Gagavuzlar, Ankara: Türk Yurdu Yayınları. 195-210.

Özdemir, A. (2004). Eski Anadolu Türkçesindeki fiillerin durum ekli tamlayıcıları. (Yüksek Lisans Tezi). Erişim adresi: https://tez.yok.gov.tr/UlusalTezMerkezi/giris.jsp.

Özkan, A. (1999). Türkçede fiil tamlayıcı ilişkisi ve fiillerin istem değiştirmesi. Arayışlar-İnsan Bilimleri Araştırmaları, 1, 125-143. Erişim adresi: https://www.academia.edu/12112389/t\%c3\%9crk\%c3\%87ede_f\%c4\%b0\%c4\%b01_tamlay

SEFAD, 2021; (45): 143-158 
1c1_\%c4\%b01\%c4\%b0\%c5\%9ek\%c4\%b0s\%c4\%b0_ve_f\%c4\%b0\%c4\%b0ller\%c4\%b0n_\%c4 \%b0stem_de\%c4\%9e\%c4\%b0\%c5\%9et\%c4\%b0rmes\%c4\%b0.

Özkan, A. (2011). Eski Anadolu Türkçesindeki bazı fiillerin hâl ekli tamlayıcıları ve bu tamlayıcılarda zaman içinde görülen değişiklikler. Türkish Studies, 6(1), 512-522. doi: 10.7827/TurkishStudies.1869

Özkan, N. (1996). Gagavuz Türkçesi grameri. Ankara: TDK Yayınları.

Özsoy, N. (1993). Eski Anadolu Türkçesinde hâl eklerinin fillerle münasebeti. (Doktora Tezi). Erişim adresi: https://tez.yok.gov.tr/UlusalTezMerkezi/giris.jsp.

Sami Şemseddin (2018). Kâmûs-ı Türkî. R. Gündoğdu, N. Adıgüzel, E. F. Önal (Haz.), İstanbul: İdeal Kültür Yayıncılık.

Sarıca, B. (2006). Türkçe'de -e /- i durum eklerinin karışması sorunu. İlmi araştırmalar Dergisi, 22, 205-218. Erişim adresi: https://dergipark.org.tr/tr/download/article-file/73591.

Sev, G. (2011). Etmek fiiliyle yapılan birleşik fiiller ve tamlayıcılarla kullanılışı. Ankara: TDK Yayınları.

Tatçı, M. (1990). Yunus Emre dîvânı. (Doktora Tezi). Erişim adresi: https://tez.yok.gov.tr/UlusalTezMerkezi/giris.jsp.

Tulum, M. (2011). 17. Yüzyıl Türkçesi ve söz varlı̆̆ı. Ankara: TDK Yayınları.

Türk Dil Kurumu (2009). Derleme sözlüğ̈̈ (C. 1-6). Ankara: Yazar.

Türk Dil Kurumu (2009). Tarama sözlü̆̆̈̈ (C. 1-8) Ankara: Yazar.

Türk Dil Kurumu (2011). Türkçe sözlük. Ankara: Yazar.

Uysal, S. (2010). Nehcü'l-Ferâdis'te kıl- fiiliyle yapılan birleşik fiiller ve tamlayıcılarla kullanılışı. (Yüksek Lisans Tezi). Erişim adresi: https://tez.yok.gov.tr/UlusalTezMerkezi/giris.jsp.

Uzunsoy, H. (2008), Türkmen Türkçesinde istem (valenz). (Yüksek Lisans Tezi) Erişim adresi: https://tez.yok.gov.tr/UlusalTezMerkezi/giris.jsp.

Yaman, E. (2000). Özbek Türkçesinde fiil tamlayıcı ilişkisi ve hâl eklerinin farklı kullanılması. IV. Uluslararası Türk dili kurultayı bildirileri (C. 2) Ankara: TDK Yayınları, 1907-1920.

Yıldız, O. (2008). Yus̄uf u Zelīhā'(Destā̄-ı Yūsuf) giriş-inceleme-metin-dizinler. Ankara: Akçağ Yayınları. 